\title{
ELECTROCHEMICAL STUDIES ON THE CORROSION BEHAVIOUR OF METALS AND ALLOYS IN SIMULATED RINGER 'S SOLUTION
}

\author{
S. Agiladevi ${ }^{1,2, *}$ and S. Rajendran ${ }^{3,4}$ \\ ${ }^{1}$ Department of Chemistry, K S R Institute for Engineering and Technology, \\ Tiruchengode-637 215, (Tamil Nadu) India. \\ ${ }^{2}$ Research and Development center, Bharathiar University, Coimbatore, India. \\ ${ }^{3}$ Research and Development center, Bharathiar University, Coimbatore, India. \\ ${ }^{4}$ Corrosion Research center, Department of Chemistry, St. Antony's College for Arts and \\ Science for Women, Thamaraipadi, Dindigul 624005,(Tamil Nadu)India \\ *E-mail: agilakarmega@gmail.com
}

\begin{abstract}
In modern History, metals and alloys have been used as implants. In the early development, metal implants faced corrosion and insufficient strength problems. Metal implants experienced vast development and clinical use. Type of metal used in biomedical depends on specific implant applications. SS316L \& Ni-Cr are still the most used alloy in all implants division ranging from Cardiovascular to Otorhinology. However, when the implant requires high wear resistance such as artificial joints, SS316L and $\mathrm{Ni}-\mathrm{Cr}$ alloys are better served. This work aims at studying the electrochemical behavior of meals like Ni-Cr, SS316L, and Gold22 \& Gold18 and for comparative purpose mild steel in the presence of Simulated Ringer Solution. The behavior of metals was mentioned by Electrochemical Impedance Spectroscopy (EIS) .All the experiments were carried out at a constant temperature at $37^{\circ} \mathrm{C}$.
\end{abstract}

Keywords: Ringer's Solution, Metal, Alloy, EIS Corrosion.

(C) RASĀYAN. All rights reserved

\section{INTRODUCTION}

Metallic materials used in orthopedics and implantology are classified as tolerable. These materials somewhere between bio-inert materials and bioactive materials. Several applications of metallic materials can be found in bio-medicine, for instance, in devices for artificial hearts, structural applications such as screws and dental implant pins and prostheses.

The demand for metallic materials in medical and dental devices is large. Metals and alloys are widely used as biomedical materials and are indispensable in the medical field. In particular, toughness, elasticity, rigidity and electrical conductivity are essential properties in medical devices, as well as biological properties (biocompatibility and bioadhesion), which are influenced by the physical, chemical and physiochemical behavior of the material. However, despite its biocompatibility, there is no formation of a bioactive layer capable of bonding with bone tissue. Thus several research projects have been developed, aimed at altering the surface of this material.

Steel, for example, is a man-made substance produced from iron oxide. The energy added in the refining process is unstable. Given a suitable environment, steel will release this energy and return to its natural state of iron ore. When immersed in an electrolyte, such as soil, water, or concrete, metals produce a current which causes ions to leave their surface. The rate of current flow determines the life of the structure. One ampere of current consumes approximately 20 pounds of iron per year ${ }^{1}$

The biomaterial is a material intended to interface with the biological system to evaluate, treat, augment or replace any tissue, organ or function of the body. Biomaterials are used in the dental implant, tooth

Rasayan J. Chem., 12(1), 22-31(2019)

http://dx.doi.org/10.31788/RJC.2019.1215037

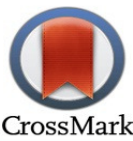


RASĀYAN J. Chem.

Vol. 12 | No. 1 |22 - 31| January - March | 2019

fillings, vascular implants, bone defect fillings, Hip joint prosthesis-bone plate, scaffolds for tissue engineering and contact lens ${ }^{2-5}$

\section{Ringer's Solution}

Ringer's analysis of the influence of blood constituents on the contraction of the frog heart (1882-1885) pioneered the general development of artificial extracellular media for maintenance of living material during in vitro physiological studies. "Ringer's solutions" are thus defined here as those designed to substitute for the blood plasma, hemolymph, or other extracellular fluids of any species with respect to variables such as ionic concentrations, $\mathrm{pH}$, and osmotic pressure. Media described in the literature as "physiological salines" and "balanced salt solutions" are included here under the general Ringer's heading. Mimicry of native conditions is achieved in varying degrees by the many different Ringers' formulations. Ringer's solutions are typically intended for relatively short-term maintenance of living material, not for its growth or extended culture. In this respect, they differ from the cell, tissue, and organ culture media, which are more complex and beyond the scope of this Compendium.

Since $\mathrm{Na}^{+}$is normally the principal extracellular ion, sodium chloride is the major component of most Ringer's solutions. Some formulations have relatively few additional ingredients but are nevertheless more complex than most "buffered saline's", consisting principally of sodium chloride and a pH buffer, presented Ions such as $\mathrm{Na}^{+}, \mathrm{K}^{+}, \mathrm{Ca}^{++}$, and $\mathrm{Mg}^{++}$are critical for many functions. Researchers initiating work are urged to select physiological solutions carefully for the particular species to be studied, and to consider developing new ones based on analysis of the natural extracellular medium. Many of Ringer's solutions $^{6-8}$, are the product of empirical testing for retention of the activity being studied. Thus, in addition to being used directly, recipes provided here can serve as a starting point for improved formulations.

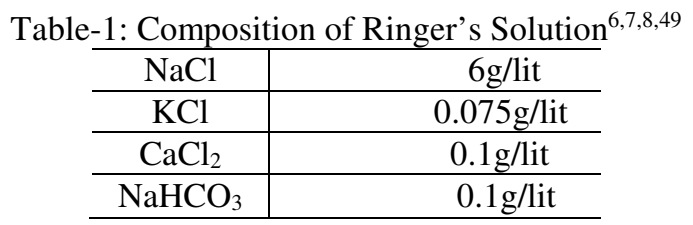

Corrosion resistance of metals and alloys in various body fluids ${ }^{48}$ such as artificial saliva ${ }^{9,10,11}$, artificial sweat ${ }^{12-14}$, blood plasma ${ }^{15-17}$, artificial urine ${ }^{18-20}$ has been investigated. The present work is undertaken to investigate the corrosion resistance of three metals namely, mild steel, 22-carat gold, 18-carat gold, Ni-Cr and SS316L in Ringer's solution by AC impedance measurements.

\section{EXPERIMENTAL}

\section{Materials and Methods}

Corrosion resistance of three metals namely Mild Steel, 18 Carat Gold and 22 Carat Gold in Ringer Solution has been investigated by AC impedance measurements. Usually, corrosion behavior of metals and alloys have been studied in Ringer solution (RS) composition ${ }^{6-8}$, is given in Table-1; Composition of Ringer's solution is given in Table- $1^{6,7,8}$, The metal specimens namely mild Steel, 22-carat gold, 18-carat gold, Ni-Cr,Stainless Steel have a composition as follows:

\section{Table-2: The Composition of the Mild Steel ${ }^{23}$}

\begin{tabular}{c|c}
\hline Carbon & $0.1 \%$ \\
\hline Manganese & $0.4 \%$ \\
\hline Phosphorous & $0.06 \%$ \\
\hline Sulfur & $0.026 \%$ \\
\hline Iron & Balance \\
\hline
\end{tabular}

Table-3: TheComposition of 22 Carat Gold ${ }^{24}$

\begin{tabular}{c|c}
\hline Gold & $91.67 \%$ \\
\hline Silver & $5 \%$ \\
\hline Copper & $2 \%$ \\
\hline Zinc & $1.33 \%$ \\
\hline
\end{tabular}


Table-4: TheComposition of 18 Carat Gold ${ }^{25}$

\begin{tabular}{c|r}
\hline Gold & $75 \%$ \\
\hline Copper & $25 \%$ \\
\hline
\end{tabular}

Table-5: TheComposition of Ni-Cr ${ }^{26}$

\begin{tabular}{c|c}
\hline Nickel & $65 \%$ \\
\hline Chromium & $27 \%$ \\
\hline Molybdenum & $5 \%$ \\
\hline Silicon & $1.5 \%$ \\
\hline C, Mn,\& B & Balance \\
\hline
\end{tabular}

Table-6: The Composition of SS316L ${ }^{27}$

\begin{tabular}{c|c}
\hline Nickel & $10-14 \%$ \\
\hline Chromium & $16-18 \%$ \\
\hline Molybdenum & $2-3 \%$ \\
\hline Silicon & $0.75 \%$ \\
\hline Manganese & $2 \%$ \\
\hline C,P \&S & Balance \\
\hline
\end{tabular}

\section{AC Impedance Measurements}

$\mathrm{H}$ and $\mathrm{CH}$ electrochemical workstation impedance analyzer model $\mathrm{CHI} 660$ was used to record $\mathrm{AC}$ impedance measurements. A three-electrode cell assembly was used. The working electrode was one of the three metals. A saturated calomel electrode (SCE) was the reference electrode and platinum was the counter electrode ${ }^{28,29}$. The real part $\left(Z^{\prime}\right)$ of the cell impedance was measured in ohms for various frequencies. The change transfer resistance $\left(R_{t}\right)$ and double layer capacitance $\left(C_{d l}\right)$ values were calculated $\mathrm{R}_{\mathrm{t}}=\left(\mathrm{R}_{\mathrm{s}}+\mathrm{R}_{\mathrm{t}}\right)-\mathrm{R}_{\mathrm{s}}$

Where $R_{\mathrm{s}}=$ solution resistance, and

$C_{\mathrm{dl}}=1 / 2 \Pi R_{\mathrm{f}} \mathrm{fmax}$

Where $f \max =$ maximum frequency.

\section{Electrochemical Impedance Spectroscopy}

The Electrochemical impedance spectroscopy (EIS) is a relatively modern technique widely extended in several scientific fields. The EIS consists on a non-destructive technique when working under equilibrium conditions (free corrosion potential or open circuit potential), particularly sensitive to small changes in the system that allows characterizing material properties and electrochemical systems even in low conductive media.

The impedance method consists in measuring the response of an electrode to a sinusoidal potential modulation of small amplitude (typically $5-10 \mathrm{mV}$ ) at different frequencies. The alternative current (AC) modulation is superimposed either onto an applied anodic potential or cathodic potential or onto the corrosion potential ${ }^{21,22,50}$

\section{Temperature}

Experiments were carried out at $37 \pm 1^{\circ} \mathrm{C}$

\section{RESULTS AND DISCUSSION}

Corrosion resistance of the metals namely mild steel, 22-carat gold, 18-carat gold Ni-Cr and SS316L in Ringer's Solution has been investigated by AC impedance measurements. AC impedance measurements have been used to investigate the formation of a protective film formed on the metal surface during corrosion process. ${ }^{28-30}$ It is well known to everyone that mild steel should not be implanted in inside the body, because it will undergo corrosion due to the electrolytes present in body fluids. However, in the present study, mild steel is used just for comparison. 
RASĀYAN J. Chem.

Vol. 12 | No. 1 |22 - 31| January - March | 2019

AC impedance parameters such as charge transfer resistance $\left(\mathrm{R}_{\mathrm{t}}\right)$, double layer Capacitance $\left(\mathrm{C}_{\mathrm{dl}}\right)$ (derived from Nyquist plots) and impedance value $\log (\mathrm{Z} / \mathrm{ohm})$ (derived from Bode plots) of various metals immersed in Simulated Ringer's Solution are given in Table-1; Nyquist plots are shown in Figs.-1,3,5 and 7 Bode plots are shown in Figs.-2, 4, 6 and 8. Table-7 presents Corrosion parameters of metals immersed in Ringer's Solution obtained from AC impedance spectra study.

\section{Mild Steel}

It is observed from Table-7; that, when mild steel is immersed in Simulated Ringer's solution (SRS), the $\mathrm{R}_{\mathrm{t}}$ value was $1062.7 \mathrm{ohm} \mathrm{cm}{ }^{2}$ and the $\mathrm{C}_{\mathrm{dl}}$ value was $1.8067 \times 10^{-8} \mathrm{~F} / \mathrm{cm}^{2}$. the impedance value $\log \mathrm{z} / \mathrm{ohm}$ is 3.104. (Fig.-1 and 2). The phase angle value 22.98 degrees (Fig.-1 and 2).
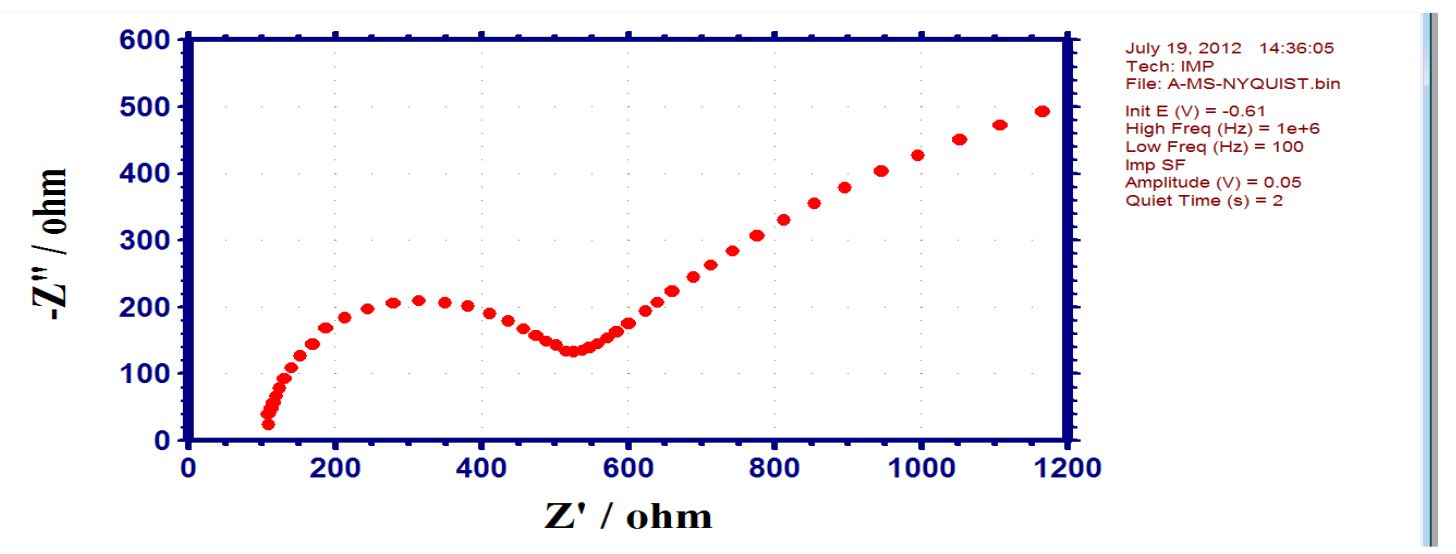

Fig.- 1: AC Impedance spectrum of mild steel immersed in SRS (Nyquist plot)
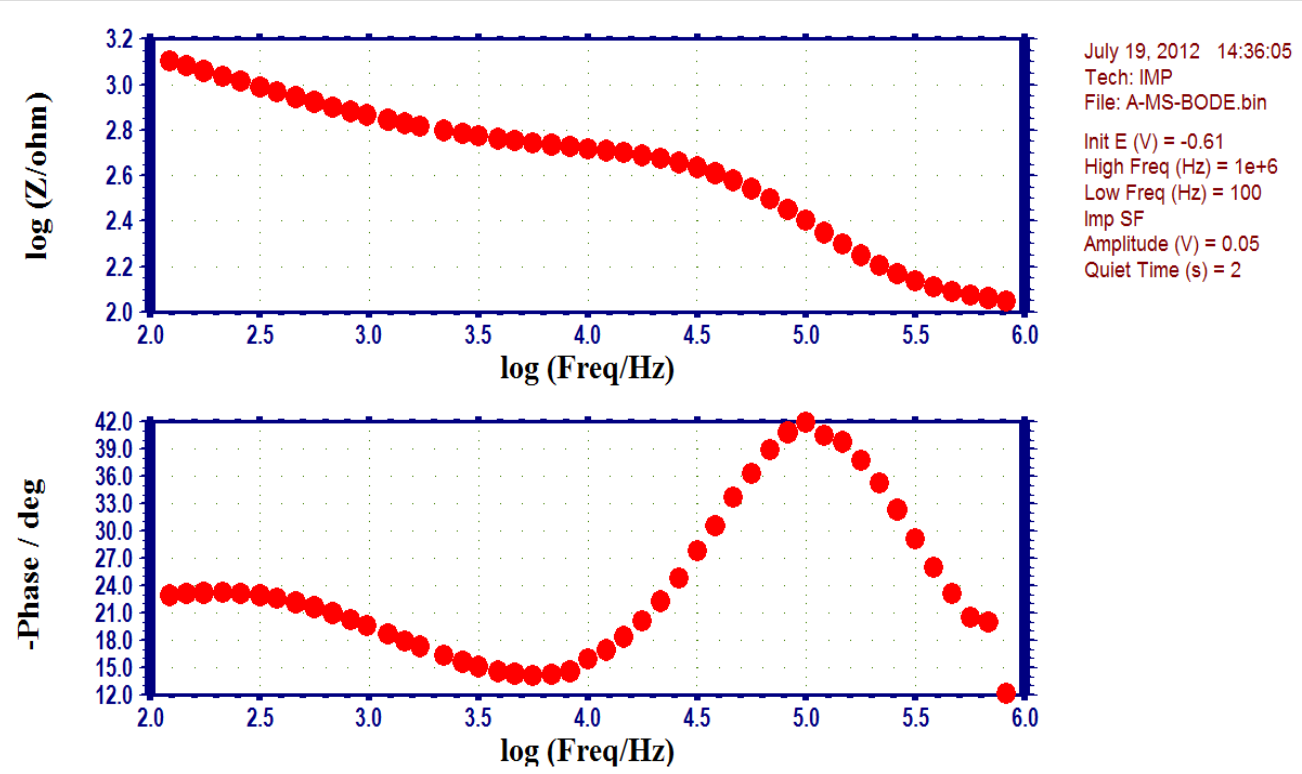

Fig.-2: AC Impedance spectrum of mild steel immersed in SRS (Bode Plot)

\section{Carat Gold}

When 18 Carat Gold is immersed in Simulated Ringer solution (SRS), the $\mathrm{R}_{\mathrm{t}}$ value is $52150 \mathrm{ohm} \mathrm{cm}^{2}, \mathrm{C}_{\mathrm{dl}}$ Value is $3.6816 \times 10^{-10} \mathrm{~F} / \mathrm{cm}^{2}$; the impedance value logs/ohm is 5.027.It is observed that the Rt value increased, cdl value decreased. There is an increase in the value of impedance $[\log (\mathrm{z} / \mathrm{ohm})]$ (Fig.-3 and 4).These observations indicate in the presence of Ringer's solution, the corrosion rate of 18 Carat Gold is reduced, due to the formation of a protective film formed on the metal surface. Because of the presence of protective film on the metal surface, electron transfer from the metal surface to the bulk of the solution 
RASĀYAN J. Chem.

Vol. 12 | No. 1 |22 - 31| January - March | 2019

was restricted. This results in an increase of charge transfer resistance and a decrease in double layer capacitance, since they are related to each other inversely.

Table-7: Corrosion parameters of metals immersed in Ringer's Solution

\begin{tabular}{c|c|c|c|c}
\hline System & $\begin{array}{c}\text { Charge Transfer Resistance }\left(\mathrm{R}_{\mathrm{t}}\right) \\
\text { Ohm.cm }\end{array}$ & $\begin{array}{c}\text { Double layer Capacitance }\left(\mathrm{C}_{\mathrm{dl}}\right) \\
\mathrm{F} / \mathrm{cm}^{2}\end{array}$ & $\begin{array}{c}\text { Impedance } \\
\text { log } \mathrm{z} / \mathrm{ohm}\end{array}$ & $\begin{array}{c}\text { Phase angle } \\
\text { degree }\end{array}$ \\
\hline Mild Steel & 1062.7 & $1.8067 \times 10^{-8}$ & 3.104 & 22.98 \\
\hline Gold 18 & 52150 & $3.6816 \times 10^{-10}$ & 5.027 & 61.60 \\
\hline Gold 22 & 286500 & $6.7015 \times 10^{-11}$ & 5.697 & 55.52 \\
\hline Ni-Cr & 781000 & $2.4583 \times 10^{-11}$ & 6.019 & 63.45 \\
\hline SS316L & 251600 & $7.6312 \times 10^{-11}$ & 5.587 & 57.58 \\
\hline
\end{tabular}

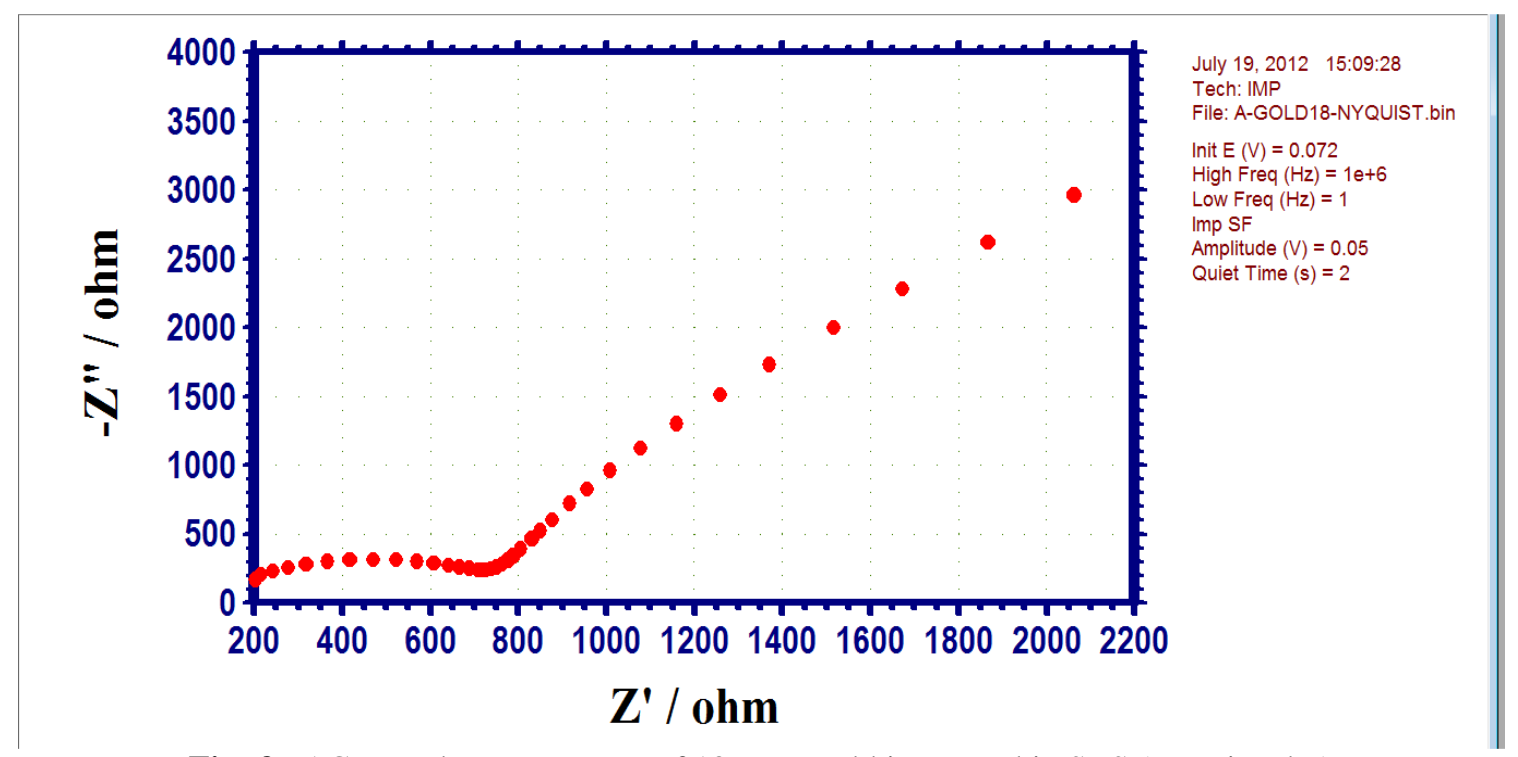

Fig.-3 : AC Impedance spectrum of 18-carat gold immersed in SRS (Nyquist plot)

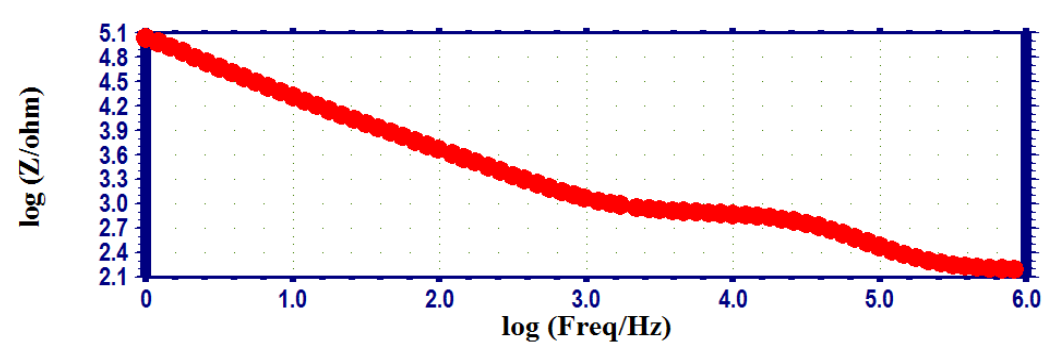

July 19, 2012 15:09:28

File: A-GOLD18-NYQUIST.bin

Init $E(V)=0.072$

High Freq $(\mathrm{Hz})=1 \mathrm{e}+6$

Low Freq $(\mathrm{Hz})=1$

Imp SF

Amplitude $(\mathrm{V})=0.05$

Quiet Time $(\mathbf{s})=2$

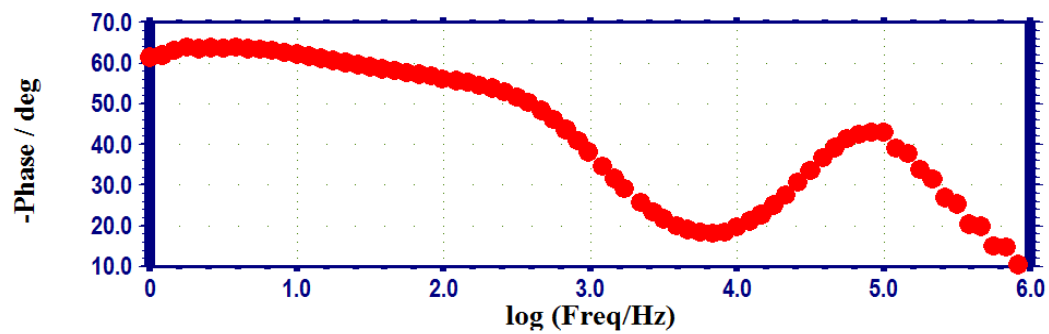

Fig.-4: AC Impedance spectrum of 18 Carat gold immersed in SRS (Bode Plot)

The equivalent circuit diagram for such a system is shown in Scheme-1. 
RASĀYAN J. Chem.

Vol. 12 | No. 1 |22 - 31| January - March | 2019

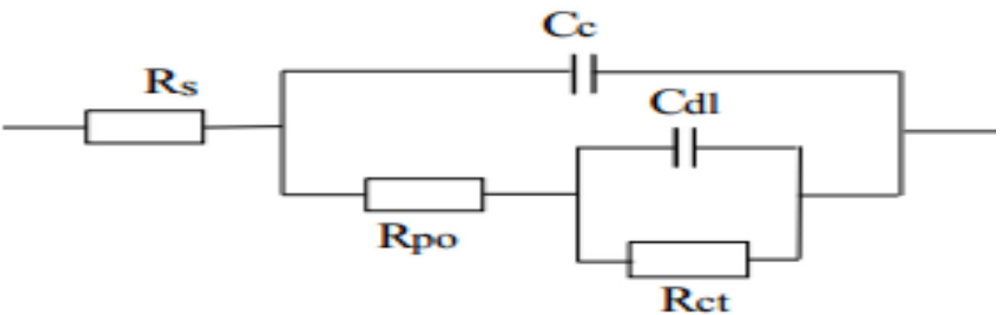

The equivalent circuit for a failed coating

$\mathrm{C}_{\mathrm{c}}$ - The capacitance of the intact coating, $\mathrm{R}_{\mathrm{po}}$ - pore resistance, $\mathrm{R}_{\mathrm{ct}}$ - charge transfer resistance, $\mathrm{R}_{\mathrm{s}}$ - solution resistance, $\mathrm{C}_{\mathrm{dl}}$ - double layer capacitance

Scheme-1

Equivalent circuit diagram for such a system is shown in Scheme-2.

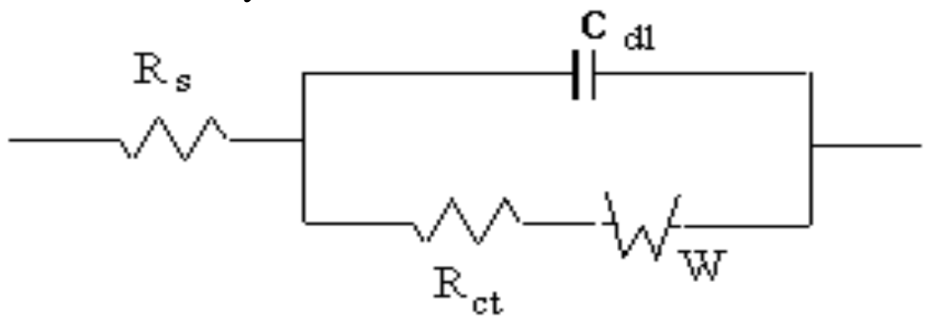

Rs - Solution resistance, Rct - Charge transfer resistance, W - Warburg diffusion resistance, Cdl - Double layer capacitance

Scheme-2

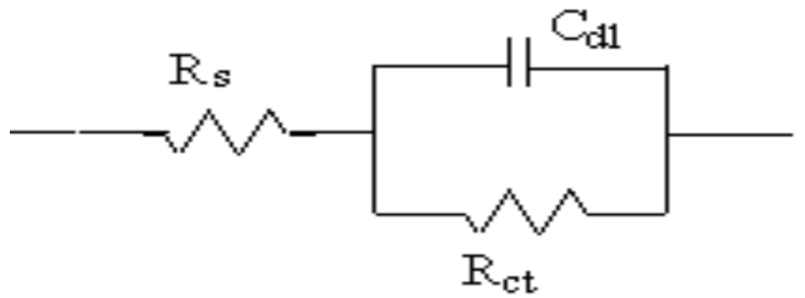

Cdl - Double layer capacitance. Rs - Solution resistance, Rct - Charge transfer resistance

Scheme-3

\section{Carat Gold}

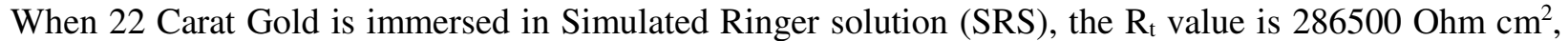
$\mathrm{C}_{\mathrm{dl}}$ Value is $6.7015 \times 10^{-11} \mathrm{~F} / \mathrm{Cm}^{2}$, the impedance value $\log \mathrm{Z} / \mathrm{Ohm}$ is 5.697.It is observed that the $\mathrm{R}_{\mathrm{t}}$ value increased and the $C_{\mathrm{dl}}$ value decreased. There is an increase in the value of impedance [log(z/ohm)](Fig. -5 and 6 ). These observations indicate in the presence of a Ringer solution, the corrosion rate of 22-carat gold is reduced, due to the formation of a protective film formed on the metal surface. Because of the presence of protective film on the metal surface, electron transfer from the metal surface to the bulk of the solution is restricted.

This results in an increase of charge transfer resistance and a decrease in double layer capacitance, since they are related to each other inversely.

\section{Nickel-Chromium}

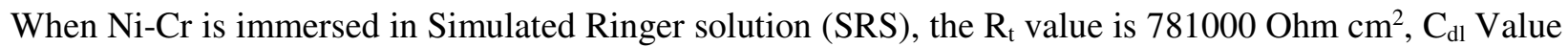
is $2.4583 \times 10^{-11} \mathrm{~F} / \mathrm{Cm}^{2}$, the impedance value $\log \mathrm{Z} / \mathrm{Ohm}$ is 6.019 .It is observed that the $\mathrm{R}_{\mathrm{t}}$ value increased and the $\mathrm{C}_{\mathrm{dl}}$ value decreased. There is an increase in the value of impedance [log (z/ohm)](Fig. -7 and 8).These observations indicate in the presence of Ringer's solution-A, the corrosion rate of Ni-Cr is reduced, due to the formation of a protective film formed on the metal surface. Because of the presence of protective film on the metal surface, electron transfer from the metal surface to the bulk of the solution is restricted. 
This results in an increase of charge transfer resistance and a decrease in double layer capacitance, since they are related to each other inversely. It is inferred that Ni-Cr is more corrosion resistant than Gold 18, Gold 22 and SS316L.This indicates the Ni-Cr is nobler than other alloys, due to the formation of a passive film on the metal surface. ${ }^{30-48}$
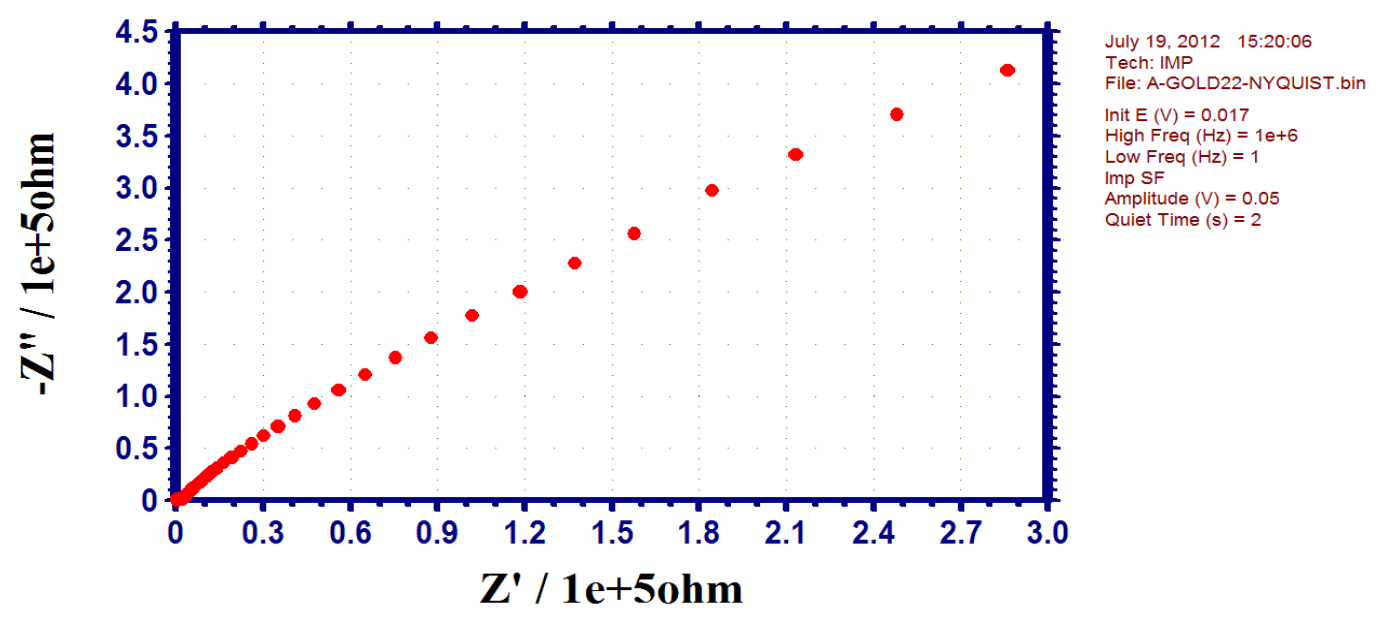

Fig. -5: AC Impedance spectrum of 22 Carat gold immersed in SRS (Nyquist plot)

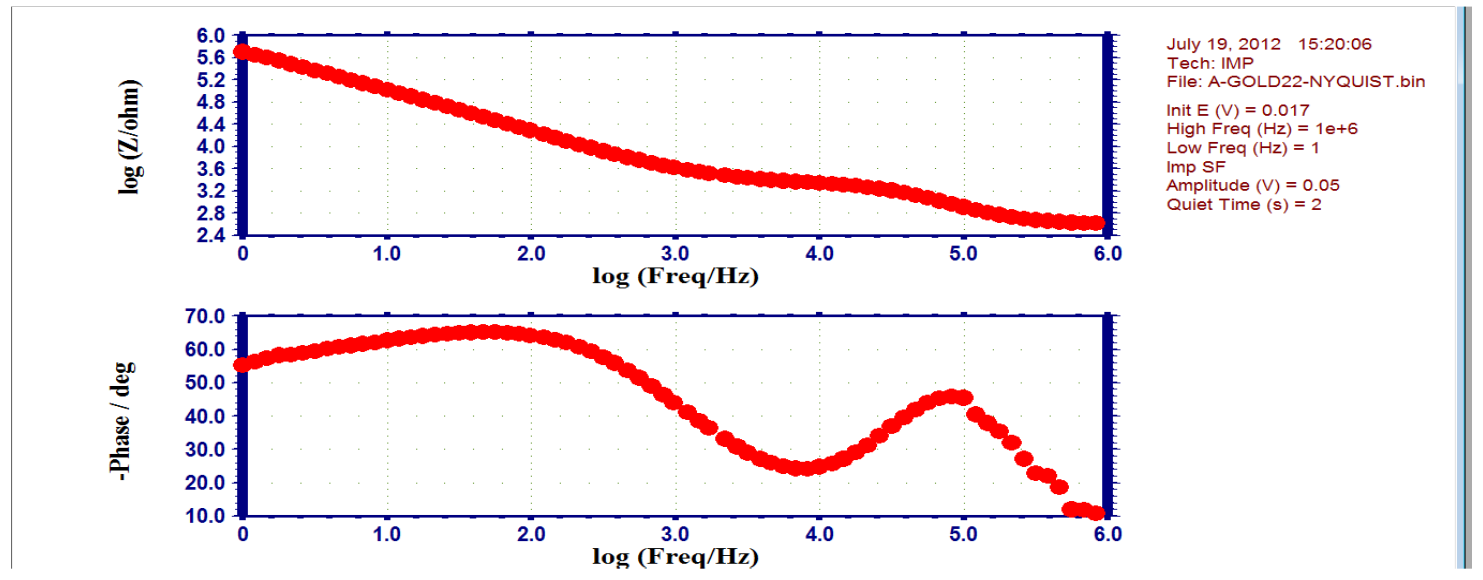

Fig.-6: AC Impedance spectrum of 22 Carat gold immersed in SRS (Bode Plot)

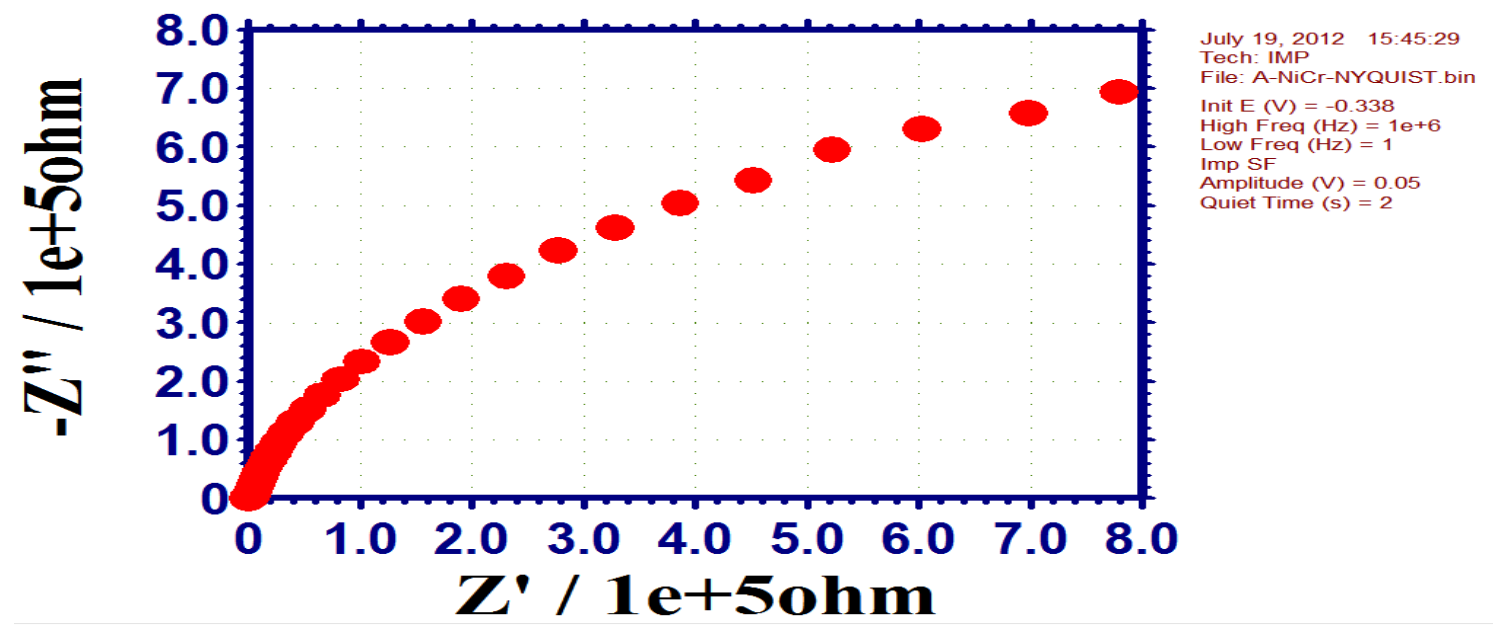

Fig.-7: AC Impedance spectrum of Nickel-Chromium immersed in SRS (Nyquist plot) 
RASĀYAN J. Chem.

Vol. 12 | No. 1 |22 - 31| January - March | 2019

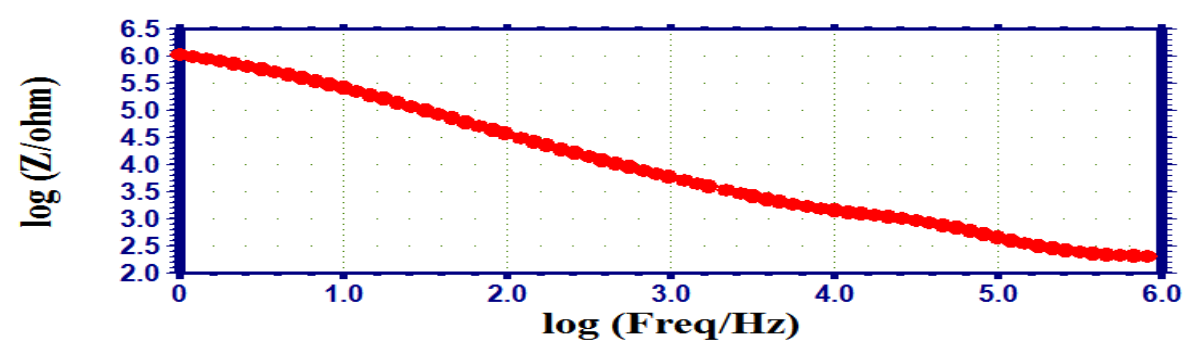

July 19, $2012 \quad 15: 45: 29$ Tech: IMP

File: A-NiCr-BODE.bin

Init $E(V)=-0.338$

High Freq $(\mathrm{Hz})=1 e^{+6}$

Low Freq $(\mathrm{Hz})=1$

Amp situde

Auiet $=0.05$

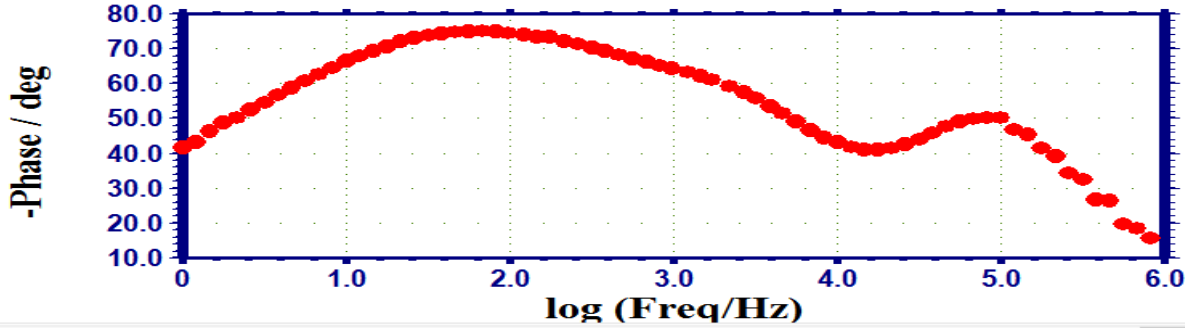

Fig.-8: AC Impedance spectrum of Nickel-Chromium immersed in SRS (Bode plot)
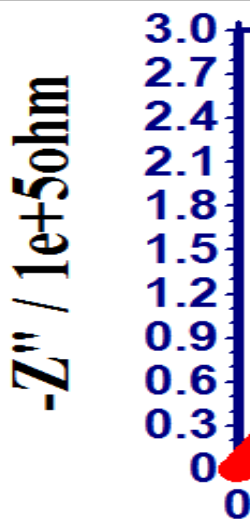

3.0
2.7
2.4
2.1
1.8
1.5
1.2
0.9
0.6
0.3
0

$0.3 \quad 0.60 .91 .21 .51 .82 .12 .42 .73 .0$

July 19, 2012 16:03:09 File: A-SS-NYQUIST.bin Init $E(V)=-0.36$ High Freq $(\mathrm{Hz})=1 \mathrm{e}+6$ Low Freq $(\mathrm{Hz})=1$ Imp SF Amplitude $(V)=0.05$ Quiet Time $(s)=2$

\section{$\mathbf{Z}^{\prime} / \mathbf{1 e + 5 o h m}$}

Fig.-9: AC Impedance spectrum of SS316L immersed in SRS (Nyquist plot)

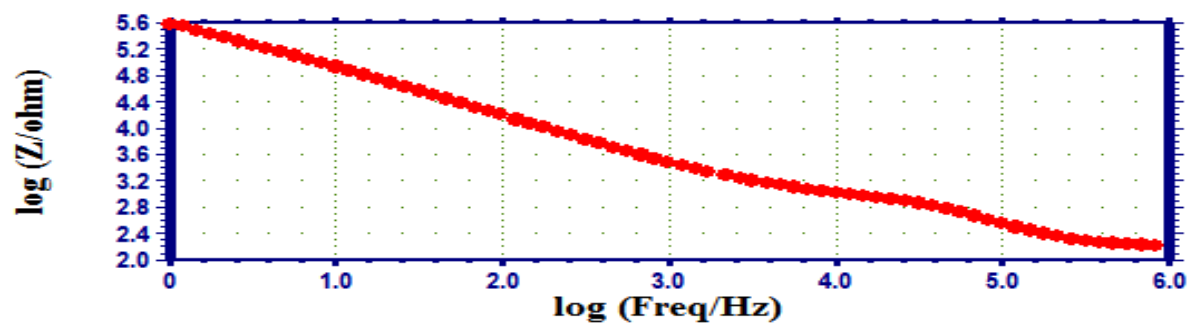

July 19, 2012 16:03:09 Tech: IMP File: A-SS-BODE. bin Init $E(V)=-0.36$ High Freq $(\mathrm{Hz})=1 \mathrm{e}+6$ Low Freq $(\mathrm{Hz})=1$ Imp SF

Amplitude $(V)=0.05$ Quiet Time (s) $=2$

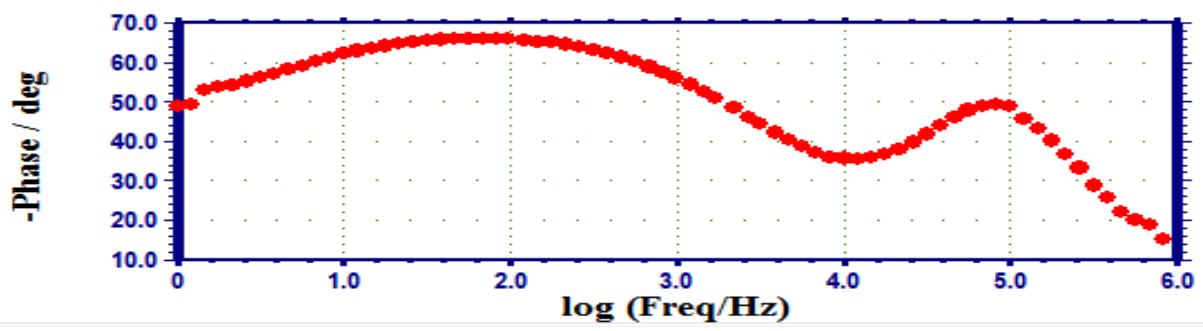

Fig.-10: AC Impedance spectrum of SS316L immersed in SRS (Bode plot)

\section{SS316L}

When SS316L is immersed in Simulated Ringer solution (SRS), the $R_{t}$ value is $251600 \mathrm{Ohm} \mathrm{cm}^{2}, \mathrm{C}_{\mathrm{dl}}$ Value is $7.6312 \times 10^{-11} \mathrm{~F} / \mathrm{Cm}^{2}$, the impedance value $\log Z / \mathrm{Ohm}$ is 5.587.It is observed that the $\mathrm{R}_{\mathrm{t}}$ value 
RASĀYAN J. Chem.

Vol. 12 | No. 1 |22 - 31| January - March | 2019

increased and the $C_{\mathrm{dl}}$ value decreased. There is an increase in the value of impedance $[\log (\mathrm{z} / \mathrm{ohm})]($ Fig. -9 and 10 ).These observations indicate in the presence of Ringer's solution, the corrosion rate of SS36L is reduced, due to the formation of a protective film formed on the metal surface. Because of the presence of protective film on the metal surface, electron transfer from the metal surface to the bulk of the solution is restricted. This results in an increase of charge transfer resistance and a decrease in double layer capacitance, since they are related to each other inversely:

\section{CONCLUSION}

Thus, AC impedance spectra lead to the conclusion that the decreasing order of Corrosion resistance of metals under investigation, in simulated Ringer solution is:

$$
\text { Ni-Cr }>\text { Gold22 > SS316L > Gold18 > Mild Steel }
$$

The above order may be explained by the fact that, there is variation in the composition of various types of alloys.

\section{ACKNOWLEDGMENT}

The authors are thankful to their respective management for their help and encouragements.

\section{REFERENCES}

1. P. E. Steven Harrigan ,The Ammtiac Quarterly,6, 10(2010)

2. T. W. Duerig, MRS Bull, 27,101 (2002)

3. S. A. Shabalovskay, Int. Mat. Rev, 46,233 (2001)

4. T. W. Duerig, A. Pelton, D. Stockel, Mater. Sci. Eng., 149, 273(1999)

5. T. W. Duerig, D. E. Tolomeo, M. Wholey, Invas. Ther. Allied. Technol, 9,235 (2000)

6. K. Satendra Kumar, T. S. N. Sankara Narayanan, J. Alloy Compd.,479, 699 (2009)

7. K. Satendra Kumar, T. S. N. Sankara Narayanan, S. Ganesh, S. Raman, S.K. Seshadri, Corros. Sci., 52, 711(2012)

8. K. Satendra Kumar, T. S. N. Sankara Narayanan, S. Ganesh, S. Raman, S. K. Seshadri, Mater. Chem.Phys.,119, 327(2010)

9. B. B. Zhang,Y. E. Zheng, Y.Liu, Dental Mater,25,672 (2009)

10. H. O. Weigman, J. A. A. Land Ketelaar, J. Dent., 15, 166 (1987)

11. L. Joska, M. Marek, J. Leitner, Biomaterials,26, 1605 (2005)

12. J. P. Randin, Biomed. J. Mater. Res., 22, 649(2008)

13. E. Budke, Krempel-Hesse, J. Surf. Coating Technol., 112, 108 (1999)

14. R. J. Rathish, S. Rajendran, S. Christy, J. L. Devi, B. S. Johnmary, S. Manivannan, M. Rajam, K. Rengan, The Open Corros. J., 3, 38(2010)

15. W. Kajzer, A. Krauze, Walke, J. Marciniak, J..Achiev.Mater.Manufact.Engg.,31, 247(2008)

16. Z. Faszenda, W. Walke, A. Ziebowicz, J. Achiev. Mater. Manuf. Engg., 28, 293 (2007)

17. W. C. Quach, P. Schmutz, Eur. Cells Mater,14, 4 (2007)

18. W. Walke, J. Przondziono, Solid State Phenomena,165, 404 (2010)

19. W. Kajzer, M. Kaczmarek, A. Krauze, J. Achiev.Mater.Manuf.Engg.,20, 123 (2007)

20. W. Kajzer, A. Krauze, W. Walke, J. Marciniak, J. Achiev. Mater. Manuf. Engg,18, 115 (2006)

21. Carlos Valero Vidal., Annaigual Munoz.,Trends in Materials Science.,13,307(2011)

22. B. E. Conway, J. Bockris, R. E. White, Edts, Kluwer academic/Plenum Publishers, pp.143-248, 32 (1999).

23. M. Pandiarajan, P. Prabhakar, S. Rajendran, ChemSci Trans, 2, 605(2013)

24. A. Nishio, S. Takahasi, N. Uchiyama, Gold Tech.,19, 11 (1996)

25. G. Raykhtsaum, D. P. Agarwal, Gold Tech.,10, 26 (1997)

26. Jean-Marc Meyer, Corrosion Science,17(12),971(1977)

27. S. John Mary, S. Rajendran, Electrochemical Acta, 31(1),33(2013)

28. B. Shyamaladevi, S. Rajendran, Euro.Chem.Bull.,1,150(2012) 
RASĀYAN J. Chem.

Vol. 12 | No. 1 |22 - 31| January - March | 2019

29. S. Rajendran,V. Uma, A. Krishnaveni, J. Jeyasundari, B. Shyamaladevi, M. Manivannan, The Arabian Journal for Science and Engineering, 34,147(2009)

30. S. Tamilselvi, R. Murugaraj, N.Rajendran, Material and Corrosion, 58,113(2007)

31. J. Felicita Florence, Susai Rajendran, K. N. Srinivasan, Electroplating and Finishing, 31, 1 (2012)

32. V. Sribharathy, S. Rajendran, CheSci Rev. Lett.,1, 25(2012)

33. C. Mary Anbarasi, S. Rajendran, Chemical Engineering Communications,199,1596(2012)

34. Vijaya Gopal Sribharathy, S. Rajendran, J. Electrochemical Sci.Eng., 2,121(2012)

35. S. Rajendran, V. Sribharathy, A. Krishnaveni, J. Jeyasundari, J. Sathiyabama, T. S. Muthumegala, M. Manivannan, Zastita Materijala, 52,163 (2011)

36. X. M. Liu, S. L. Wu, Paul. K. Chu., Applied Surface Science.,253,3154 (2007)

37. Peng Wan.,Yibin Ren., Bingchun Zhang., Ke Yang., Material Science and Engineering, 32,510 (2007)

38. Y. Yesu Thangam. M. Kalanithi. C. Mary Anbarasi, S. Rajendran, The Arabian Journal for Science and Engineering, 34, 49(2009)

39. S. Agnesia Kanimozhi. S. Rajendran, Int. J. Electrochem. Sci, 4, 353(2009)

40. J. Sathiyabama, S. Rajendran, J. Jeyasundari, B. Shyamaladevi, Journal of Engineering Science and Technology,3, 27 (2010)

41. V. Johnsirani, S. Rajendran, J. Sathiyabama, T. S. Muthumegala, A. Krishnaveni, N. Hajara Beevi, Bulgarian Chemical Communications, 44, 41(2012)

42. A. Nithya, S. Rajendran, Bulgarian Chemical Communications, $\mathbf{4 2 , 1 1 9 ~ ( 2 0 1 0 ) ~}$

43. Noreen Anthony, H. Benita Sherine, Susai Rajendran.,The Arabian Journal for Science and Engineering, 35, 41 (2010)

44. V. Johnsirani, J. Sathiyabama, Susai Rajendran, A.Suriya Prabha, International Scholarly Research Network Corrosion, 10, 1(2012)

45. S. Tamilselvi, N. Rajendran, Trends in Biomaterials and Artificial Organs, 20,1 (2006)

46. M. Sangeetha, S. Rajendran, J. Sathiyabama, P. J. Prabhakar, Nat. Prod.PlantResour,2,601 (2012)

47. S. Rajendran, C. Thangavelu, T. Venkatesh, DerChemica Sinica,3,1475 (2012)

48. S. Rajendran, K. Anuradha, K. Kavipriya, A. Krishnaveni, J. Angelin Thangakani, Eur. Chem.Bull.1, 503(2012)

49. J. Xu, X. Bao, S. Jiang. Jinshu Xuebao/Acta Metallurgica Sinica,54(3), 443 (2018)

50. S. Bose, L.C. Pathak, R. Singh. Applied Surface Science, 433, 1158(2018)

51. J.Cassar, B. Mallia, A. Karl, J. Buhagiar. Materials Science and Engineering C ,75,1366 (2017)

[RJC-5037/2018] 